ISSN: $1579-9794$

\title{
Interferencia en la traducción francés/español de textos de ciencias sociales
}

\section{(Interference in the translation of Social Sciences texts from French into Spanish)}

\author{
Beatriz EMILCE CAGNOLATI \\ beatrizcagnolati@gmail.com \\ Instituto de Investigaciones en Humanidades y Ciencias Sociales (IdIHCS) \\ Universidad Nacional de La Plata (Argentina)
}

Fecha de recepción: 2 de julio de 2015

Fecha de aceptación: 2 de octubre de 2015

Resumen: La interferencia está presente en todo proceso de traducción y se hace visible en el producto discursivo a través de las desviaciones de prácticas normales y codificadas del sistema meta - transferencias negativas- como así también de las características similares que existen y se utilizan en los sistemas de partida y llegada - transferencias positivas- (Toury, 2004: 345). En el último caso, los resultados son difícilmente identificables puesto que la producción se corresponde con el sistema y las normas de la lengua-cultura de llegada; en cambio, las transferencias negativas se visibilizan como contaminación y su incidencia puede ir desde la elevación de la frecuencia de ciertos elementos sin infringir la norma (Sinner, 2004: 73), que dificultan el ajuste entre la expresión y el contenido por transmitir, hasta el desacierto derivado de la falta de correspondencia entre las lenguas-cultura puestas en juego. De allí que se requiera de esfuerzos especiales del traductor con la finalidad de disociar y contrarrestar los mecanismos discursivos automáticos. Generalmente, la enseñanza de la traducción especializada se centra en la búsqueda terminológica, en la investigación temática, y desatiende la expresión sintáctica pues esta formaría parte de las competencias lingüísticas adquiridas cuya producción es automática. En este trabajo se expondrán los criterios que se han tenido en cuenta para describir las anomalías sintácticas y discursivas en enunciados elípticos de textos traducidos de ciencias sociales por influencia de la interferencia. 
Palabras clave: Interferencia, Traducción, Producción discursiva, Enunciados elípticos, Anomalía sintáctica, Anomalía discursiva, Binomio textual.

Abstract: Interference is present in every translation process and becomes visible in the discourse product through deviations from the normal and codified practices of the target system -negative transferences- as well as in the similar features that exist and are used in both source and target systems -positive transferences (Toury, 200: 345). In the latter case, the results are hardly identifiable because the production corresponds to the system and the norms of the target language-culture; on the other hand, negative transferences become visible as a contamination and their incidence can go from the growth in the frequency of certain elements without breaking the norm (Sinner, 2004: 73) which complicates the adjustment between the expression and the content to be transmitted-, to the mistake derived from the lack of correspondence between the languages-cultures at stake. This is why special efforts are required from the translator in order to dissociate and counteract automatic discourse mechanisms. Usually, the teaching of specialized translation focuses on terminological search, on thematic research, and neglects syntactic expression, for this would be part of the acquired linguistic competences, whose production is automatic. In this paper, we shall enumerate the criteria which have been taken into account in order to describe the syntactic and discourse anomalies in elliptic statements from translated Social Sciences texts by the influence of interference.

Keywords: Interference, Translation, Discourse production, Elliptic statements, Syntactic anomaly, Discourse anomaly, Textual pairing.

\section{INTRODUCCIÓN}

El tema de este artículo se origina en la experiencia de lectura y revisión de traducciones especializadas del francés al español, provenientes de los cursos de traducción del último año de formación universitaria, como así también de traducciones de circulación interna y publicadas. En estas producciones, frecuentemente se identifican enunciados que requieren repetidas lecturas para ajustar la expresión con la información que transmiten. Siguiendo la metáfora del palimpsesto, parecería que esos fragmentos conservan la presencia de una escritura previa y ajena al texto traducido.

Tales observaciones indicarían que en la fase de producción discursiva o reformulación se han producido anomalías en algún campo del sistema de la 
lengua o seleccionado formas lingüísticas alejadas de las normas de uso, de carácter sociocultural. Debido a la polisemia de la palabra anomalía, en este trabajo se la asociará operativamente con la perseveración u ocurrencia reiterada de un elemento sintáctico y con la dificultad en el manejo de elementos de cohesión (Silvestri, 2000: 168). En especial, se la aplicará a la siguiente clasificación: elipsis con anomalías sintácticas o gramaticales y elipsis con anomalías discursivas. En el primer caso, se reúnen las elipsis que no siguen el sistema lingüístico de referencia (en este caso el español) y en el segundo las elipsis que, aun resueltas dentro del sistema lingüístico de llegada, inciden negativamente en el pasaje de la información.

Dado que la interferencia es un término que refiere a un mecanismo omnipresente en los estudios que implican lenguas en contacto en sentido amplio, es decir, en la relación entre lengua materna y lenguas extranjeras, en el fenómeno de bilingüismo y también en el proceso de traducción (Sánchez, 2005: 159-173), se presentarán definiciones canónicas y reflexiones sobre su incidencia en la traducción escrita. Luego, se expondrán los criterios establecidos para el análisis de las anomalías sintácticas y discursivas vinculadas con la producción de elipsis, y se describirá la tabla de análisis generada, aplicándola a algunos ejemplos del corpus constituido por dos publicaciones de Bioética, original en francés y su traducción al español.

\section{INTERFERENCIA: UNA NOCIÓN SIN LÍMITES PRECISOS}

La noción de interferencia nace en la Física ondulatoria y migra a diversas disciplinas en calidad de préstamo interno. En el caso de la Lingüística, su presencia se registra en el IV Congreso Internacional de Lingüistas celebrado en Copenhague en 1936.

Sin embargo, su empleo no es uniforme, lo que puede llevar a malentendidos e interpretaciones no acertadas, como lo consigna Sinner (2004: 58). En este sentido, se observan dos cuestiones: por un lado, la inexistencia de un concepto con límites precisos puesto que la interferencia se hace visible mediante cambios lingüísticos de cualquier nivel, sea entre dos lenguas o dos registros dentro de una misma lengua, sea como sociolecto o idiolecto; por otro lado, una noción evolutiva que va de la consideración de la interferencia desde una concepción aleatoria o de aparición imprevista hacia una concepción no aleatoria o sistemática que obedece a reglas precisas.

En 1953, Uriel Weinreich se constituye en el primer antecedente que inserta los problemas lingüísticos del bilingüismo en el campo de la sociolingüística, al considerar la existencia de causas "no estructurales" que 
inciden en la interferencia, ya sea para inhibirla o favorecerla (Blas Arroyo, 1996: 19). Sostiene además, que los mecanismos de la interferencia son los mismos cualquiera sea el grado de lejanía o cercanía estructural de las lenguas en contacto y vincula su visibilidad en el habla de las personas bilingües con la desviación de las normas ${ }^{1}$ de las lenguas en contacto:

Those instances of deviation from the norms of either language which occur in the speech of bilinguals as a result of the familiarity with more one language, i.e. as a result of language contact, will be referred to as INTERFERENCE phenomena. II is these phenomena of speech, and their impact on the norms of either language exposed to contact, that invite the interest of the linguist ([1953] 1963: 1) 2 .

Desde la definición formulada por Weinreich, la interferencia ha sido interpretada como error ${ }^{3}$, especialmente en el terreno de la adquisición de lenguas extranjeras. Sin embargo, como señala Sinner, la influencia ejercida por una lengua sobre otra no lleva necesariamente a una infracción de la norma sino, a veces, a "una elevación de la frecuencia de uso de ciertos elementos". (2004: 73).

Dentro de la lingüística contrastiva y de la clásica división entre versión fuerte predictiva que confirma o refuta el conjunto de los contrastes de las lenguas que se estudian y versión débil, testimonial y explicativa, Ronald Wardhaugh (1991) adscribe a esta última, pues toma los fenómenos de la interferencia lingüística como punto de partida para explicar contrastivamente

1 En 1962 Coseriu formula el modelo tripartito (sistema-norma-habla) en la primera edición de Teoría del Lenguaje y lingüística general-la versión consultada es de 1989- y ve en la norma un sistema de realizaciones obligadas, de imposiciones sociales y culturales que varía según la comunidad; es decir que dentro del mismo sistema funcional o lengua, coexisten varias normas, lenguaje familiar, popular, especializado, entre otros, siendo entonces la norma, una limitante más fuerte que el sistema (98). El concepto coseriano de norma se refiere al cómo se dice, normal/anormal, y no al cómo se debe decir, correcto/incorrecto (90).

${ }^{2}$ Los casos de desviación de las normas de cualquiera de las lenguas que ocurren en el habla de los bilingües, como resultado de la familiaridad con más de una lengua, es decir como resultado del contacto de lenguas, serán referidos como fenómenos de INTERFERENCIA. Estos fenómenos del habla, y su impacto en las normas de cualquier lengua expuesta al contacto, son los que interesan al lingüista (nuestra traducción).

${ }^{3}$ Stephen P. Corder (1991) diferencia el error de la falta: distingue los errores de actuación que se caracterizan por ser asistemáticos y los errores de competencia que son sistemáticos. El autor designa falta a los errores de actuación y error a los de competencia o sistematicidad, señalando que esta es transitoria en el proceso de aprendizaje.

Hikma 14 (2015), 55-74 
los sistemas implicados; entre esos fenómenos, se señalan la traducción imperfecta y las dificultades de aprendizaje (41-49). De manera análoga, William Nemser (1991) se inclina por la versión débil pues esta da cuenta de la dinámica del aprendizaje: la interferencia en el análisis contrastivo está comprendida dentro de una visión general del aprendizaje que sostiene que toda adquisición previa afecta la siguiente, ya sea positivamente, cuando coinciden sus dominios, o de forma negativa, cuando estos se oponen. El primer caso se denomina transferencia positiva y el segundo transferencia negativa (51-61) ${ }^{4}$.

Por su parte, en el estudio sobre la influencia de la lengua materna en la adquisición de la lengua extranjera, Santos Maldonado afirma que generalmente las similitudes de las lenguas en contacto son las que generan más problemas (2002: 152) y Domínguez Vázquez señala que se ha puesto de relieve la incidencia unidireccional de la lengua materna sobre la extranjera; sin embargo la lengua extranjera, L2, también influye sobre la lengua materna, L1, especialmente cuando existe dominio de la L2, lo que daría cuenta de la bidireccionalidad de la interferencia (2001: 11).

En lo que respecta a las clasificaciones de las interferencias, estas reflejan la evolución de los estudios lingüísticos: un primer momento tradicional, en que estos estaban orientados a la palabra y extendidos hasta la oración y un segundo momento en el que se incluyen los niveles discursivo y pragmático, 0 contextual, en sentido amplio. De ello resulta que la clasificación tradicional postula la existencia de interferencia fonética, gramatical y léxica, mientras que la clasificación contextual incluye los enfoques discursivos, pragmáticos y culturales, todos ellos interactuando en el proceso de traducción.

\section{INTERFERENCIA EN LA TRADUCCIÓN}

La interferencia estudiada desde la lingüística en su relación con las lenguas en contacto como efecto natural de situaciones sociales — caso de la

\footnotetext{
${ }^{4}$ Resulta útil la adaptación realizada por María Jesús Santos Maldonado (2002: 56) sobre la terminología y los casos de contraste español/francés, en base a la jerarquización de estructuras gramaticales inglés/español de D. Larsen-Freeman y M.H. Long que sintetizan algunos de los problemas generados por las transferencias negativas. Las dificultades identificadas son:

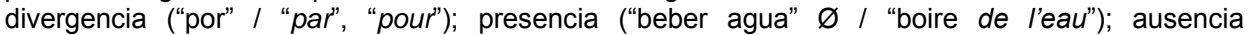
(pronunciación de la $r$ final en los verbos de primera conjugación "cantar"/ sin pronunciación "chanter"); convergencia ("ser" y "estar"/ "être"); equivalencia (marca de género y número "las flores blancas" / "les fleurs blanches").
} 
inmigración- por un lado, o como efecto de la adquisición de lenguas extranjeras, por otro lado, presenta puntos en común con la interferencia en traducción, ya que esta última supone, en primer lugar, el contacto de dos sistemas lingüísticos con especificidades conceptuales y morfosintácticas propias, haciendo uso de los cuales, el traductor resuelve problemas de índole lingüístico-textual y cultural o pragmático. En adquisición de lenguas extranjeras, la influencia de la lengua materna es inconsciente o difícilmente controlable, ya sea en el proceso de acercamiento a la nueva lengua, en el almacenamiento de las unidades lingüísticas y de sus reglas morfosintácticas de combinación, como también en los hábitos de la lengua materna.

Por su parte, García Yebra (1997: 359) ve en la interferencia lingüística del traductor efectos análogos a los que aparecen en el contacto interlingüístico, por debilidad en el conocimiento o dominio de la lengua propia, mientras que Delisle y Bastin postulan que cuanto mayor es el conocimiento lingüístico de quien traduce, menor será el riesgo de interferencia, de allí que el perfeccionamiento lingüístico sea considerado como una actividad individual y progresiva en la que el trabajo contrastivo encuentra su espacio (1997: 46).

En lo que hace al macroproceso de la traducción escrita, esquemáticamente, este implica dos fases —comprensión y producción discursiva o reexpresión - atravesadas por el universal de interferencia que condiciona los mecanismos discursivos relacionados con la memoria (Toury, 2004: 345). Generalmente, la interferencia es considerada como contaminación de la lengua-cultura desde la que se traduce hacia la lengua-cultura meta, y su visibilidad es mayor en lenguas de familias cercanas puesto que la similitud estructural contribuye a reducir el esfuerzo de reexpresión.

Con respecto a la manera de traducir, la clásica obra Stylique comparée du français et de l'anglais establece una diferencia entre los procedimientos de traducción directos o literales (préstamo, calco, traducción literal) y los oblicuos (transposición, modulación, equivalencia, adaptación). Los primeros son de sencilla resolución y están más ligados al texto original que los segundos (Vinay y Darbelnet, 1958: 46-54).

A título ilustrativo, el préstamo o extranjerismo acusa un apego al texto original, que puede entenderse ya sea como esfuerzo mínimo o bien como decisión de crear una atmósfera de exotismo en la lengua-cultura de llegada: "aprisiona su mirada en el espesor del khol" (Beauvoir, El Segundo Sexo, traducción de Palant, 1981: 202).

Por otra parte, los discursos especializados son receptivos a las expresiones cultas que ponen de manifiesto un conocimiento compartido. Se 
citan a continuación ejemplos tomados de Au bazar du vivant $>$ El racismo del gen (Testart y Godin, traducción de Goldstein): in vitro, p. 52; status, p. 17; a fortiori, p. 32; a priori, p. 46; homo sapiens, p. 106. Asimismo, como caso especial de préstamo, pueden consignarse las siglas: ICSI, intracytoplasmic sperm injection > microinyección de un espermatozoide en un óvulo, p. 108; FIVETE, fécondation in vitro et transfert embryonnaire > fecundación in vitro y transferencia embrionaria, p. 13; IVG, interruption volontaire de la grossesse > interrupción voluntaria del embarazo, p.45.

En cuanto al préstamo naturalizado, este remite a formas que son tomadas de otras lenguas, pero que se adaptan fonética o morfológicamente a la lengua-cultura de llegada: restaurante, profiteroles, p. 45.

El segundo procedimiento directo, el calco, indica que un sintagma del polo de partida es sometido a una traducción literal, es decir un recurso asociado a la lengua-cultura del texto original. El resultado es la conservación de la estructura sintáctica superficial de origen expresada en palabras de la lengua meta: le grand public > el gran público, p. 80; Galton avait les deux casquettes > Galton tenía "las dos gorras", p. 51.

Estos sencillos ejemplos proporcionan el marco para avanzar sobre la interferencia que se visibiliza a través de la transferencia positiva y negativa.

Al respecto, Toury (2004: 269, 346-349) concibe la interferencia como un universal de la traducción o mecanismo por defecto, cuya visibilidad varía según la manera en que se ajusta una traducción a la configuración del texto original, ya sea desde los niveles más bajos o, por el contrario, holísticamente. Su enfoque sobre la interferencia toma en cuenta la raíz psicolíngüística del fenómeno, que es uno solo, pero con manifestaciones negativas o positivas. El primer caso, las desviaciones de prácticas normales y codificadas del sistema meta hacen notoria la visibilidad porque está emparentada con las nociones de error, fallo o anomalía. En cambio, si la transferencia es positiva a causa de la mayor probabilidad de seleccionar características que existen y se utilizan en ambas lenguas-cultura, la visibilidad de la interferencia solo será posible si se contrasta el texto original con el texto traducido. Además, en el proceso de traducción escrita, permanentemente se efectúa un vaivén entre el discurso de partida y las reglas del sistema de la lengua meta; ese movimiento obstaculiza la individualización del polo que generó la transferencia negativa pues los indicios pueden ser bidireccionales (Cagnolati, 2010: 326). 


\section{CORPUS TEXTUAL Y ALCANCE DEL ESTUDIO}

El corpus textual constituido consiste en una recopilación de originales relativamente actuales de textos pragmáticos ${ }^{5}$ y sus traducciones publicadas. Los autores de los textos originales (TO) son de lengua materna francesa y quienes produjeron los textos escritos (TT) tienen el español como lengua materna. El campo del saber es la Bioética, cuyo discurso interdisciplinario se ve poblado de términos provenientes de diferentes enfoques biológicos, filosóficos, morales que están plasmados lingüísticamente con una sintaxis compleja, propia de las ciencias sociales.

Las fuentes son, por un lado, los originales en francés y sus traducciones al español publicados en soporte electrónico ${ }^{6}$ y, por el otro, la obra original en papel de Testart, Jacques y Godin, Christian (2001), Au bazar du vivant, Paris, Seuil y su traducción bajo el título El racismo del gen (2002), realizada por Víctor Goldstein, Buenos Aires, Fondo de Cultura Económica.

La lectura de estas traducciones hacia el español como escritura de primera mano mostró que la opacidad en la transmisión de la información estaba asociada, cuantitativamente, a los enunciados con vacíos léxicos, muchos de los cuales respondían al concepto de elipsis, definida por Brucart como mecanismo limitador de la redundancia léxica (2000: 2789).

Se analizaron, por un lado, las elipsis sintácticas cuya construcción no responde a las normas del sistema lingüístico de llegada y por el otro, las elipsis bien resueltas sintácticamente, pero que dificultan la cohesión y por consiguiente la transmisión de la información.

\section{INSTRUMENTO DE ANÁLISIS}

\begin{tabular}{|c|c|c|c|c|}
\hline \multirow{6}{*}{ 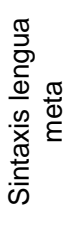 } & \multirow{3}{*}{ Tipo de elipsis } & \multirow[t]{2}{*}{ nominal } & total & \multirow{2}{*}{$\begin{array}{l}\text { Sujeto } \\
\text { OD, OI, otra. }\end{array}$} \\
\hline & & & parcial & \\
\hline & & \multicolumn{3}{|c|}{ verbal } \\
\hline & Elemento elidido & \multicolumn{3}{|c|}{$\begin{array}{c}\text { identificación de sus rasgos (virtualidad), en } \\
\text { especial en elipsis nominal. }\end{array}$} \\
\hline & Construcción de la elipsis & \multicolumn{3}{|c|}{ gramatical, con anomalía sintáctica. } \\
\hline & Recuperabilidad & \multicolumn{3}{|c|}{ oracional, transfrástica. } \\
\hline
\end{tabular}

\footnotetext{
${ }^{5}$ Jean Delisle (1984: 22), con criterio amplio, designa textos pragmáticos a aquellos que brindan información sin búsqueda estética.

${ }^{6}$ Recursos electrónicos disponibles en línea en la página web: http://www.genethique.org/.
} 


\begin{tabular}{|c|c|c|}
\hline 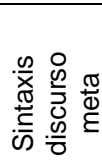 & Cohesión - coherencia & $\begin{array}{l}\text { eliminación de la posible virtualidad detectada } \\
\text { en sintaxis de la lengua meta; } \\
\text { recuperabilidad del valor léxico de la elipsis; } \\
\text { repercusión en la construcción de sentido }\end{array}$ \\
\hline 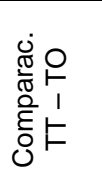 & $\begin{array}{r}\text { Análisis de la prod } \\
\text { Análisis de la proc } \\
\text { Posible extensión de las cons } \\
\text { Verificación del }\end{array}$ & $\begin{array}{l}\text { ción del segmento problema en TO; } \\
\text { cción del segmento solución en TT; } \\
\text { Discusión; } \\
\text { nencias de la anomalía microestructural; } \\
\text { ncipio traducir toda la información. }\end{array}$ \\
\hline 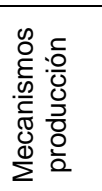 & $\begin{array}{l}\text { Observación a partir de la } \\
\text { producción discursiva del TT }\end{array}$ & $\begin{array}{c}\text { elevación de la frecuencia de uso (recursos o } \\
\text { elementos); } \\
\text { control lingüístico de la lengua-cultura meta; } \\
\text { control lingüístico-discursivo. }\end{array}$ \\
\hline \multirow{2}{*}{$\begin{array}{l}\frac{0}{0} \\
\frac{\pi}{7} \\
\frac{T}{5} \\
0 \\
\mathbb{0} \\
\simeq\end{array}$} & Visibilidad de interferencia & $\begin{array}{c}\text { del sistema lingüístico meta; } \\
\text { del discurso origen; } \\
\text { otra. }\end{array}$ \\
\hline & \multicolumn{2}{|c|}{$\begin{array}{l}\text { Fenómeno sintáctico visible; } \\
\text { Alcance discursivo; } \\
\text { Producción palimpséstica; } \\
\text { Entropía informativa. }\end{array}$} \\
\hline
\end{tabular}

Partiendo de la lectura del corpus textual traducido al español, se elaboró esta tabla que combina, por un lado, el análisis de enunciados elípticos cuya construcción o aparición complejiza el pasaje de información y, por el otro, el origen de la interferencia visibilizada.

La tabla contiene el apartado Sintaxis de la lengua meta que reúne datos sobre el tipo de elipsis (nominal o verbal), su alcance total o máximo si involucra todo un sintagma, o parcial si opera sobre el núcleo léxico de un sintagma. En el caso de las elipsis nominales, estas pueden ser de argumento externo o sujeto, elipsis de argumento interno u OD, OI, predicativo, complemento adnominal. Los ítems siguientes corresponden a la identificación de los rasgos del elemento elidido, a la gramaticalidad o anomalía en la construcción de la elipsis y, por último, al criterio de recuperabilidad del antecedente elidido, que puede situarse en la misma oración o en posición transfrástica.

De inspiración coseriana, el apartado Sintaxis del discurso meta responde al hecho de que la traducción se resuelve en el plano discursivo según las decisiones que va tomando el traductor (habla), en las que este pone 
en juego sus conocimientos lingüísticos del sistema y de uso o norma. Se contempla entonces el análisis de los enunciados elípticos en la lengua y en el discurso meta. En este último caso, se rastrea la recuperación del antecedente puesto que, a pesar de que una elipsis esté resuelta adecuadamente a nivel oracional, puede también repercutir negativamente en la construcción de sentido.

En cuanto a la Comparación del binomio TT-TO, esta se realiza a través del análisis y discusión de la producción del segmento problema en el TO y de la producción del segmento solución en el TT, en donde calcula, por un lado, la posible extensión de las consecuencias de la anomalía microestructural a niveles macro o superestructurales y, por el otro, la verificación de la traducción de la totalidad de la información del TO.

En el caso de los Mecanismos de producción, se ha adscripto a la postura cognitiva que sostiene que los mecanismos de emisión de las formas lingüísticas informan parcial, retrospectiva e indirectamente sobre la resolución de un problema de traducción. Se tomó como insumo la información de los puntos anteriores (Sintaxis de la lengua meta, Sintaxis del discurso meta, Comparación del binomio TT-TO) y para interpretarla, se recurrió a conceptos operativos fácilmente observables, puesto que las características del corpus impiden realizar hipótesis acerca de cómo leyó el traductor el TO para llegar a su producción. Los ítems que conforman este apartado son: la elevación de la frecuencia de uso de elipsis y su relación con la infracción de la norma; el control lingüístico de la lengua-cultura meta que indica el esfuerzo por deshacerse de los significantes del TO para evitar la traducción literal con consecuencias negativas. Por último el control lingüístico-discursivo que indica si el traductor ha realizado el esfuerzo por deshacerse de los significantes del TO, para evitar anomalías discursivas, tanto endofóricas como exofóricas.

El último apartado Resultado está destinado a identificar la visibilidad de la interferencia en el TT, respondiendo a los siguientes interrogantes:

¿Qué interferencia gobierna el enunciado traducido? ¿Proviene del sistema lingüístico meta?, ¿del discurso origen?

¿Cuál es el fenómeno sintáctico visible y qué repercusión discursiva tiene?, que recoge la información de Sintaxis de la lengua meta, Sintaxis del discurso meta, Comparación del binomio TT-TO.

¿Qué grado de libertad tiene la producción? La producción palimpséstica se entiende como presencia en el TT de huellas de un texto ajeno que obstaculizan la construcción de sentido y requieren la verificación con el TO. 
¿Se ha cumplido el precepto traducir toda la información? Si la respuesta es negativa, hay entropía informativa.

\subsection{Aplicación de la tabla}

A modo de aplicación, en este trabajo se analizarán tres binomios textuales de dos de las fuentes textuales ya citadas $A u$ bazar du vivant $>E I$ racismo del gen (véase apartado 3. "Corpus textual y alcance del estudio"). El género discursivo secundario o complejo de pertenencia es la entrevista, que incluye como una de sus características la presencia de expresiones informales entre complejos conceptos que desarrollan dos participantes del intercambio dialógico -un filósofo y un investigador en Biología- durante el juego intersubjetivo, tratando de restituir la espontaneidad del intercambio directo en las formas escritas (Arfuch, 1995).

A la izquierda, se consigna la traducción y a la derecha el texto de partida, con la finalidad de representar espacialmente que la primera lectura fue la traducción.

\begin{tabular}{|c|c|}
\hline Texto traducido & Texto original \\
\hline $\begin{array}{l}\text { Por lo tanto, tras una breve presentación } \\
\text { de su carrera y de su trabajo, } \\
\text { encararemos sucesivamente esas tres } \\
\text { cuestiones: la metamorfosis de la } \\
\text { biología, la metamorfosis de la medicina } \\
\text { y la crítica de la bioética. Cap.1. p.11 }\end{array}$ & $\begin{array}{l}\text { Donc, après une brève présentation de } \\
\text { votre carrière et de votre travail, nous } \\
\text { aborderons successivement ces trois } \\
\text { questions: la métamorphose de la } \\
\text { biologie, la métamorphose de la } \\
\text { médecine et la critique de la bioéthique. } \\
\text { Ch. } 1, \text { p. } 9\end{array}$ \\
\hline
\end{tabular}

SINTAXIS DE LA LENGUA:

-Tipo de elipsis: Adjunto extraclausular temporal con elipsis nominal parcial (argumento de sustantivo): su carrera [Ø], su trabajo [Ø].

-Elemento elidido: En la oración no quedan identificados los rasgos básicos del poseedor ( $i 3^{\underline{a}}$ persona del singular género masculino?, $i 3^{\underline{a}}$ persona del singular género femenino?, ¿ $2^{a}$ persona "usted", $3^{a}$ persona plural?).

-Construcción de la elipsis: Construcción gramatical.

-Recuperabilidad: El antecedente no es recuperable en el nivel oracional. 
SINTAXIS DEL DISCURSO:

-Eliminación de la posible virtualidad detectada: El posesivo tiene dos rasgos característicos ya que constituye una proyección del pronombre y además toma la posición de especificador, concordando con el número del núcleo del SN; por lo tanto en todo determinante posesivo hay una relación anafórica con el poseedor. El posesivo antepuesto realiza la función semántica del argumento del nombre que corresponde al genitivo (poseedor, agente o tema) (Picallo y Rigau, 2000: 980).

-Recuperabilidad del valor léxico de la elipsis: La recuperación de un referente puede realizarse ya sea endofóricamente, por los mecanismos de anáfora (antecedente) o catáfora (consecuente), o bien en el contexto en que se produce el enunciado; en este último caso el antecedente se interpreta deícticamente.

-El género discursivo original fue la entrevista que tiene a la ostensión como una de las características de oralidad. El texto analizado es producto de la transcripción de la entrevista, por lo tanto, aquella característica desaparece.

-En el caso analizado, la recuperación del posesivo "su" es transfrástica pues el antecedente "usted" aparece 15 renglones antes.

-Repercusión en la construcción de sentido: La recuperación de la referencia se debilita por la imposibilidad de ostensión y por la morfología compartida del posesivo "su" entre la tercera persona (él/ella y sus plurales) y la segunda (usted/es).

COMPARACIÓN DEL BINOMIO TO-TT

-El TO produce la forma posesiva «votre» correspondiente a la segunda persona que se diferencia de la de tercera persona, lo que facilita la recuperación del antecedente, aunque no haya ostensión.

-EI TT produce la forma "su" con un debilitamiento de la cohesión como se ha explicado en Sintaxis del discurso.

MECANISMOS DE PRODUCCIÓN DISCURSIVA DEL TT

-Elevación de la frecuencia de uso de recursos o elementos, en nuestro caso la elipsis que está asociada a la ausencia léxica.

-Descenso de control lingüístico-discursivo: el uso de posesivos "su/sus" repercute en la cohesión. Traducción automática, desde niveles bajos.

RESULTADO

-Visibilidad de interferencia del sistema lingüístico meta (uso de su/sus). 
-Visibilidad de interferencia del discurso de partida (votre/su).

-Elipsis dentro del sistema con consecuencias discursivas: argumento de sustantivo.

-Descenso de la cohesión con consecuencias en la búsqueda del referente.

-Producción palimpséstica.

\begin{tabular}{|c|c|}
\hline Texto traducido & Texto oriainal \\
\hline $\begin{array}{l}\text { Jacques Testart: Efectivamente, con } \\
\text { frecuencia se hace ideología, pero ¿no } \\
\text { es un poco lo que hace Atlan cuando } \\
\text { pretende que el resultado de una } \\
\text { clonación humana (...). La higiene del } \\
\text { lenguaje, en efecto, permitiría suprimir } \\
\text { palabras fuertes, pero, al mismo tiempo, } \\
\text { ¿no corre el riesgo de volver insulso el } \\
\text { mismo contenido de dichas palabras, es } \\
\text { decir, también las representaciones que } \\
\text { vehiculizan y que no están desprovistas } \\
\text { de sentido? Cap.1, p. } 14\end{array}$ & $\begin{array}{l}\text { Jacques Testart: On fait effectivement } \\
\text { de l'idéologie, mais n'est-ce pas aussi } \\
\text { un peu ce que fait Atlan quand il prétend } \\
\text { que le résultat d'un clonage humain (...). } \\
\text { L'hygiène du langage permettrait, } \\
\text { effectivement, de supprimer des mots } \\
\text { forts, mais ne risque-t-on pas en même } \\
\text { temps d'affadir le contenu même de ces } \\
\text { mots, c'est-à-dire aussi les } \\
\text { représentations qu'ils véhiculent et qui } \\
\text { ne sont pas dénuées de sens? Ch. } 1, p \text {. } \\
13\end{array}$ \\
\hline
\end{tabular}

\section{SINTAXIS DE LA LENGUA META}

-Tipo de elipsis: Construcción verbal con elipsis nominal máxima (argumento externo o sujeto): ¿no $\varnothing$ corre el riesgo...?

-Elemento elidido: En la oración no quedan identificados los rasgos básicos del argumento sujeto elidido ( $¿ 2^{\mathrm{a}}$ persona "usted"? ${ }^{2} 3^{\mathrm{a}}$ persona singular?).

-Construcción de la elipsis: Construcción gramatical.

-Recuperabilidad: El antecedente no es recuperable en el nivel oracional.

\section{SINTAXIS DEL DISCURSO}

-Eliminación de la posible virtualidad detectada: Las virtualidades sobre la persona del argumento sujeto de "corre el riesgo" referidas en Sintaxis de la lengua meta quedan circunscriptas a la tercera persona singular, correspondiente a la forma impersonal.

-Recuperabilidad del valor léxico de la elipsis: A pesar de que la interrogación retórica está sintácticamente bien construida en el nivel oracional, al pasar a la dinámica discursiva, no es posible la recuperación endofórica del SN sujeto de "corre el riesgo", que remite transfrásticamente al inicio de la intervención de Jacques Testart: "Efectivamente, con frecuencia se hace ideología". 
-Repercusión en la construcción de sentido: Si se tomara automáticamente como SN sujeto a "La higiene del lenguaje", el resultado sería semánticamente incoherente puesto que la higiene del lenguaje no es el agente que "corre el riesgo" sino el medio que puede dar como resultado "correr el riesgo de" debilitar el contenido de ciertas palabras.

COMPARACIÓN DEL BINOMIO TO-TT

-En el TO la palabra que abre la intervención de Jacques Testart es el pronombre indefinido cuya función es sujeto "On», que se repite en la interrogación retórica "ne risque-t-on pas», lo que delimita precisamente el alcance de cada uno de los sujetos de la oración (On fait, (...) L'hygiène du langage, ne risque -t-on).

-En el TT el lugar sujeto está vacío, siendo posible identificar que esa carencia fue resuelta con el incremento de la partícula "se" en función de sujeto impersonal, al comienzo de la intervención de Jacques Testart, lo cual lleva a considerar este caso como una falsa elipsis. La posición tendría que llenarse con una forma de valor semántico-referencial indeterminada (se corre el riesgo/la gente corre el riesgo/uno corre el riesgo).

MECANISMOS DE PRODUCCIÓN DISCURSIVA DEL TT

-Elevación de la frecuencia de uso de recursos o elementos, en nuestro caso la elipsis que está asociada a la ausencia léxica.

-Descenso del control lingüístico-discursivo: la ausencia léxica no instaura elipsis de sujeto pues no es posible recuperar anafóricamente un antecedente. Traducción automática, desde niveles bajos.

RESULTADO

- Visibilidad de interferencia del sistema lingüístico meta, es decir el castellano.

-Falsa elipsis dentro del sistema con consecuencias discursivas: argumento externo o sujeto elipsis (ne risque-t-on pas/corre el riesgo). Se pone en evidencia al comparar el TT con el TO.

-Descenso de cohesión con consecuencias en la construcción de sentido.

\section{Ejemplo 3}

\begin{tabular}{|c|c|}
\hline Texto traducido & Texto original \\
\hline $\begin{array}{l}\text { Pero a ese fatalismo se agrega } \\
\text { contradictoriamente una especie de } \\
\text { sueño voluntarista que descansa en la }\end{array}$ & $\begin{array}{lll}\text { Or à ce fatalisme } & \text { s'adjoint } \\
\text { contradictoirement une espèce } & \text { de rêve } \\
\text { volontariste reposant sur l'idée } & \text { (qui est }\end{array}$ \\
\hline
\end{tabular}


idea (que es una loca esperanza) de que podría gobernarse a los genes e incluso (en un trivial sentido comercial) encargar genes. Cap.3, p. 55 une folle espérance) que l'on pourrait commander aux gènes et même (en un sens trivial commercial) commander des gènes. Ch. 3 , p. 67

SINTAXIS DE LA LENGUA META

-Tipo de elipsis: Construcción coordinada cuyo segundo miembro produce elipsis del verbo modal y elipsis nominal máxima (argumento externo o sujeto): podría gobernarse a los genes e incluso (...) [Ø] encargar genes.

-Elemento elidido: En la oración de base no quedan identificados los criterios paralelísticos.

-Construcción de la elipsis: Construcción con anomalía sintáctica.

-Recuperabilidad: El antecedente es recuperable en el nivel oracional.

SINTAXIS DEL DISCURSO

-La coordinación está incluida en una conjuntiva tradicionalmente llamada completiva "la idea (...) de que (...)". En el primer miembro de la coordinación, el infinitivo "gobernar" incluye la partícula clítica polifuncional "se".

Al respecto, Di Tullio (1997: 178) observa que la forma "se" instaura ambigüedad de análisis cuando el verbo está en singular, según la función que se le atribuya al SN: si se lo toma con función sujeto, "se" + verbo conforman pasivas pronominales; en cambio, si el SN es analizado como OD, el "se" es impersonal. Sin embargo, como el SN OD "a los genes" está introducido por la preposición "a", no puede transformarse en sujeto de pasiva pronominal, de allí que la partícula "se" es impersonal.

-El análisis es distinto en el segundo miembro: el SN plural está pospuesto al verbo, introducido directamente, sin preposición ni determinante. En cuanto a la concordancia del verbo modal elidido poder, hay divergencia de opiniones: María Luisa Olsen y Alicia María Zorrilla (1997: 934) consideran que en la pasiva refleja con se, el auxiliar modal seguido de infinitivo con complemento directo debe concordar con el número del objeto directo. En cambio, Amaya Mendikoetxea (2000: 1711) expresa que si bien en una construcción con se pasivo el verbo modal generalmente concuerda con el objeto nocional del verbo infinitivo, al mismo tiempo propone una doble estructura sintáctica con y sin concordancia.

-La coordinación es una relación simétrica apta para la elipsis, a diferencia de la subordinación que es asimétrica. Una condición fundamental para lograr una elipsis es el paralelismo estricto entre sintagma con núcleo elidido y sintagma 
que contiene el antecedente: ambos deben contener los mismos especificadores, complementos y adjuntos del núcleo. Los que tengan valor coincidente forman el hueco y el resto está integrado por unidades que adoptan valores distintos a los de la oración que contiene el antecedente (Brucart, 2000: 2807). Dentro del concepto amplio de elipsis, la reducción de sintagma verbal coordinado es el mecanismo que afecta al verbo y al sujeto en las estructuras coordinadas.

-En este caso, el hueco está constituido por el modal "podría" y el incremento pronominal "se", siendo el resto "encargar genes" en el segundo miembro de la coordinada que no tiene la misma estructura - ausencia de determinante y de preposición- del primer miembro de la coordinación "a los genes"; es decir, no hay paralelismo entre los miembros de la coordinación.

\section{COMPARACIÓN DEL BINOMIO TO-TT}

-El TO utiliza el sujeto indefinido «on» + verbo modal «pourrait» + infinitivo, + $\mathrm{SP}(\grave{a}+$ les $=a u x)+$ gènes coordinado al segundo verbo infinitivo con elipsis del modal y del sujeto indefinido pero con la presencia del infinitivo "commander» seguido del determinante «des». Es decir, utiliza los dos regímenes aptos para el mismo verbo "commander» indirecto (aux gènes) y directo (des gènes), y obtiene una expresión simétrica y cohesiva.

-EI TT presenta una estructura análoga a la del TO, con el auxiliar modal podría + el infinitivo "gobernar" incrementado con la partícula "se", como equivalencia del pronombre indefinido o arreferencial "On» + SN OD con preposición "a los genes". Sigue la coordinación "e incluso" como equivalencia de "et même» + el segundo verbo infinitivo "encargar" con elipsis del auxiliar modal + OD "genes", sin determinante, como traducción automática del indeterminado "des». A diferencia del TO, el TT no registra un verbo como "commander», con los dos significados según el régimen directo o indirecto. EI TT consigna dos formas equivalentes a los significados evocados por el TO pero sin hacer las transformaciones sintácticas necesarias para su funcionamiento en el texto de llegada.

MECANISMOS DE PRODUCCIÓN DISCURSIVA DEL TT

-Elevación de la frecuencia de uso de recursos o elementos, en nuestro caso la elipsis que está asociada a la ausencia léxica.

-Descenso del control lingüístico: El sistema francés ofrece el verbo "commander à» y "commander» que pueden corresponden en castellano a "gobernar" y "encargar", con las transformaciones sintácticas que la producción 
necesite. La forma plural de los artículos indeterminados en francés es «des» = "unas", "unos" en castellano. El uso difiere: en francés, generalmente, los núcleos están determinados, mientras que el castellano admite más frecuentemente formas nominales sin determinantes -especialmente los indeterminados-, al menos en la variante rioplatense.

-Descenso del control lingüístico-discursivo: traducción automática, puesto que no se han generado las transformaciones correspondientes al cambio de verbo "gobernarse", "encargar", ni tampoco evaluado las consecuencias de la ausencia del indeterminado "unas", "unos" o la posibilidad de su reemplazo por el determinado "los".

RESULTADO

- Visibilidad de interferencia de la lengua de partida (on).

-Visibilidad de interferencia del discurso de partida (commander aux commander des).

-Falsa elipsis fuera del sistema con consecuencias discursivas: argumento externo o sujeto elipsis que se pone en evidencia al comparar el TT con el TO. Inexistencia de paralelismo.

-Descenso de cohesión con consecuencias discursivas.

-Producción palimpséstica.

\section{CONCLUSIONES}

Los binomios estudiados, entre los cuales este artículo ha tomado una muestra de tres, son los enunciados traducidos que requirieron más de una lectura o una verificación con el texto original, con la finalidad de ajustar lo expresado con la información transmitida.

En todos ellos se reveló la ocurrencia de elipsis sintácticas y discursivas, aunque las primeras fueron marcadamente menos numerosas que las discursivas, lo cual es consistente con el presupuesto de que quien asume la responsabilidad de traducir conoce las reglas de los sistemas lingüísticos puestos en juego.

Entre los resultados más evidentes, se destaca, en primer lugar, que la interferencia del sistema de la lengua materna en el texto traducido es principalmente visible en la elipsis nominal máxima de sujeto. Se sabe que una diferencia contrastiva global entre los sistemas lingüísticos francés/castellano reside en que las construcciones oracionales del primero implican la conservación del sintagma nominal sujeto mientras que el español puede elidirlo, ya que su rico sistema de desinencias verbales recupera los rasgos de 
persona y número del sujeto pronominal que no aparece con forma fonética en la oración (lenguas pro-drop para la gramática generativa). Este hecho explica que las anomalías de las elipsis en función sujeto sean habitualmente discursivas, puesto que una morfología verbal idéntica genera un producto discursivo ambiguo, si el enunciado en el que está contenido el verbo en cuestión admite más de un candidato como sujeto; es decir, que aunque estructuralmente la producción responda a las reglas del sistema, la cohesión disminuye (ej. 2).

En segundo lugar, la presencia de anomalías discursivas como producto de la interferencia bidireccional. La bidireccionalidad se manifiesta como vaivén entre el discurso de partida y las reglas del sistema de la lengua meta, en este caso el español que coincide con la lengua materna del traductor. Así, en el corpus se ha comprobado que la bidireccionalidad se manifesta negativamente cuando el discurso de origen ha sido excesivamente respetado, con una producción basada en una correspondencia únicamente lingüística, que ciertamente está vinculada con un modo de procesamiento ascendente, revelador de soluciones automáticas (ej. 1 y 2 ).

En tercer lugar y con muy baja frecuencia, la presencia de fragmentos con anomalías sintácticas, que acusan interferencia del discurso de partida sobre la producción discursiva en español (ej. 3).

La práctica traductora de textos escritos en general y especializados en particular, demuestra la sucesión ininterrumpida de lecturas (local y global) y especialmente el vaivén entre las lecturas del texto original y la escritura, seguida de lecturas parciales del nuevo texto en otra lengua-cultura. Esta situación desestabiliza la idea que equipararía la producción de un texto con la de un texto traducido puesto que además de la libertad condicionada que implica una traducción, el universal de interferencia está presente en todo el proceso traductivo. En esta encrucijada compleja pero también lúdica, el esfuerzo se concreta en los controles que van más allá de la búsqueda y resolución de problemas temáticos y terminológicos, e involucran asimismo la expresión sintáctica, a veces desatendida por el hecho de que forma parte de las competencias automáticas de expresión.

La lectura de textos traducidos, considerándolos como una producción discursiva de primera mano, su posterior confrontación con el texto original y la organización y generalización de los resultados constituyen una herramienta de utilidad en la formación de traductores. 


\section{REFERENCIAS BIBLIOGRÁFICAS}

BeauvolR, Simone de, El Segundo Sexo, traducción de Pablo Palant. Buenos Aires: Siglo XX, 1981

BLAS ARROYO, José Luis, La interferencia lingüística en Valencia (dirección, catalán - castellano). Castelló de la Plana: Universitat Jaume I, 1996.

BRUCART, José María, "La elipsis". En: Gramática descriptiva de la lengua española. Madrid: Real Academia Española / Espasa Calpe, 2000, pp. 2787-2863.

CAGNOLATI, Beatriz, La producción discursiva en la traducción de textos pragmáticos francés/castellano: estudio traductológico a través de los enunciados elípticos con anomalías. Tesis Doctoral. Facultad de Humanidades y Ciencias de la Educación, Universidad Nacional de La Plata, 2010. Disponible en línea en:

http://www.memoria.fahce.unlp.edu.ar/tesis/te.359/te.359.pdf [Fecha de consulta: 20 de mayo de 2015].

COSERIU, Eugenio, Teoría del lenguaje y Lingüística general. Madrid: Gredos, 1989.

DOMíNGUEZ VÁZQUEZ, María José, "En torno al concepto de interferencia". En: Círculo de Lingüística Aplicada a la Comunicación, 5, 2001.

Disponible en línea en: www.ucm.es/info/circulo/no5/dominguez.htm [Fecha de consulta: 25 de junio de 2015].

DELISLE, Jean, L'analyse du discours comme méthode de traduction. Ottawa: Éd. de I'Université d'Ottawa, 1984.

DELISLE, Jean; BASTIN, Georges, Iniciación a la traducción. Enfoque interpretativo. Teoría y práctica. Caracas: Universidad Central de Venezuela, 1997.

DI TULLıO, Ángela, Manual de gramática española. Buenos Aires: Edicial, 1997.

GaRcía YeBrA, Valentín, Teoría y práctica de la traducción. Madrid: Gredos, 1997.

GILE, Daniel, La traduction. La comprendre, l'apprendre. Paris: PUF, 2005.

MENDIKOETXEA, Amaya, "Construcciones inacusativas y pasivas". En: Gramática descriptiva de la lengua española. Madrid: Real Academia Española / Espasa Calpe, 2000, pp.1575-1629.

NEMSER, William, "Los sistemas aproximados de los que aprenden lenguas segundas". En: La adquisición de las lenguas extranjeras. Madrid: Visor, 1991, pp. 51-61.

OLSEN, María Luisa; ZoRRILLA, Alicia María, Diccionario de los usos correctos del español. San Pablo: Estrada, 1997. 
Picallo, María Carmen; Rigau, Gemma, "El posesivo y las relaciones posesivas". En: Gramática descriptiva de la lengua española. Madrid: Real Academia Española / Espasa Calpe, 2000, pp. 973-1023.

SÁNCHEZ, Ida Sonia, "La Traductología: Estudio de Lenguas en Contacto". En: Hermeneus, 7, 2005, 159-173.

SANTOS MALDONADO, María Jesús, El error en las producciones escritas de francés lengua extranjera: análisis de interferencias léxicas y propuestas para su tratamiento didáctico. Universidad de Valladolid, 2002.

Disponible en línea en: http://www.cervantesvirtual.com/nd/ark:/59851/bmcv69c3. [Fecha de consulta: 15 de junio de 2015].

SEIB, Jörg, La variedad bilingüe del español hablado en Cataluña caracterizada por interferencias y convergencias con el catalán. Mannheim: Universität Mannheim, Diplomarbeit, 2001. Disponible en línea en: www.carstensinner.de/castellano/trabajosineditos.html. [Fecha de consulta: 25 de junio de 2015].

SILVESTRI, Adriana, La adquisición discursivo-cognitiva en la escuela secundaria. Habilidades de reformulación y estrategias de memoria. Buenos Aires: Universidad de Buenos Aires, 2000.

SINNER, Carsten, El castellano de Cataluña Estudio empírico de aspectos léxicos, morfosintácticos, pragmáticos y metalingüísticos. Tübingen: Max Niemeyer Verlag GMBH, 2004.

TESTART, Jacques y GODIN, Christian, Au bazar du vivant. Paris: Seuil, 2001.

-, El racismo del gen, traducción al español de Víctor Goldstein. Buenos Aires: Fondo de Cultura Económica, 2002.

TOURY, Gideon, Los estudios descriptivos de traducción y más allá. Metodología de la investigación en estudios de traducción, traducción al español de Rosa Rabadán y Raquel Merino. Madrid: Cátedra, 2004.

VINAY, Jean-Paul; DARBELNET, Jean, Stylistique comparée du français et de l'anglais. Paris: Didier, 1958.

WARDHAUGH, Ronald, "La hipótesis del análisis contrastivo". En: La adquisición de las lenguas extranjeras. Madrid: Visor, 1991, 41-49.

WeINREICH, Uriel, Languages in Contact. La Haya: Mouton \& Co, [1953] 1963. 